
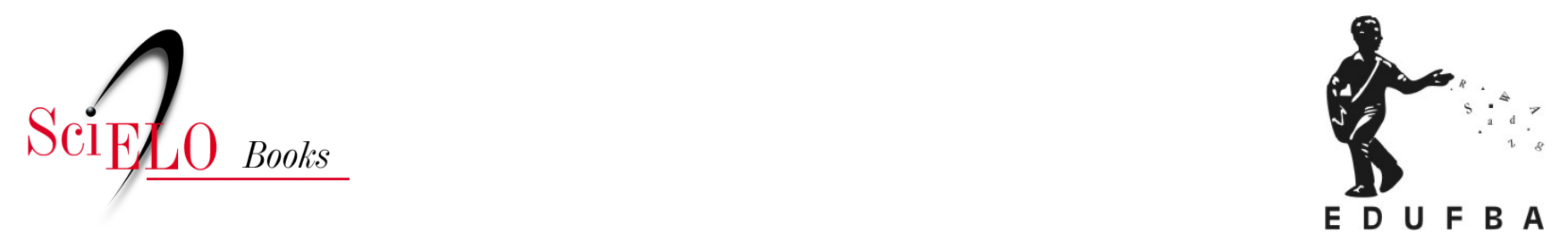

\title{
Policy \\ Atenção primária e saúde bucal: as evidências de sua implementação no Brasil
}

\author{
Sandra Garrido de Barros \\ Maria Guadalupe Medina \\ Daniela Lemos Carcereri \\ Diana Carolina Ruiz \\ Ana Carolina Oliveira Peres
}

\section{SciELO Books / SciELO Livros / SciELO Libros}

BARROS, S.G., MEDINA, M.G., CARCERERI, D.L., RUIZ, D.C., and PERES, A.C.O. Atenção primária e saúde bucal: as evidências de sua implementação no Brasil. In: CHAVES, S.C.L. Política de saúde bucal no Brasil: teoria e prática [online]. Salvador: EDUFBA, 2016, pp. 173-202. ISBN 978-85-232-2029-7. https://doi.org/10.7476/9788523220297.0007. \section{International license.}

All the contents of this work, except where otherwise noted, is licensed under a Creative Commons Attribution 4.0

Todo o conteúdo deste trabalho, exceto quando houver ressalva, é publicado sob a licença Creative Commons Atribição 4.0. 



\title{
Atenção primária e saúde bucal
} AS EVIDÊNCIAS DE SUA IMPLEMENTAÇÃO NO BRASIL

\author{
Sandra Garrido de Barros \\ Maria Guadalupe Medina \\ Daniela Lemos Carcereri \\ Diana Carolina Ruiz \\ Ana Carolina Oliveira Peres
}

\section{Introdução}

No Brasil, a atenção básica é definida como um conjunto de ações de saúde, individuais e coletivas, que incluem promoção e proteção da saúde, prevenção de doenças, diagnóstico, tratamento, reabilitação, redução de danos e manutenção da saúde. Por meio da implementação de tais ações por equipes de saúde responsáveis por populações adstritas, de modo articulado com os demais níveis e pontos de atenção do sistema de saúde, pretende-se desenvolver uma atenção integral que favoreça a autonomia dos sujeitos e estimule a participação comunitária, com efeitos positivos sobre os determinantes sociais e sobre a saúde das populações de forma global. (BRASIL, 2012a)

A Política Nacional de Atenção Básica (PNAB), desde 2006, vem sendo considerada como estratégia prioritária para expansão e consolidação desse nível do sistema de saúde brasileiro. (BRASIL, 2011) A principal estratégia para a reorganização e consolidação da atenção básica no Sistema Único de Saúde (SUS) e seguindo seus princípios tem sido a Estratégia Saúde da Família (ESF), a qual busca a reorientação do modelo assistencial, mediante o trabalho em equipes multiprofissionais de saúde. (BRASIL, 2012a) Apesar da importância conferida à atenção básica nos documentos normativos do SUS, existe uma 
série de tensões entre uma visão abrangente de Atenção Primária à Saúde (APS), afinada com os preceitos da Declaração de Alma-Ata, segundo a qual a APS deve ser reconhecida como coordenadora do cuidado, primeiro contato com o sistema, e responsável pela atenção integral dos indivíduos ao longo do tempo (IOM, 1978; STARFIELD,1979, 2002), e uma visão restrita, que entende APS apenas como um pacote mínimo de serviços para grupos sociais excluídos, focado nas doenças mais prevalentes, desenho induzido por agências financiadoras internacionais em diferentes países. (VILASBOAS et al., 2015)

Como forma de reorganizar a APS no Brasil, o Ministério da Saúde (MS) lançou, em 1994, o Programa Saúde da Família (PSF). Em um contexto de ajuste fiscal e reformas setoriais na saúde, o programa ganhou ampla aceitação nacional, com o objetivo de superar os limites do modelo vigente, particularmente na esfera municipal. (BRASIL, 1997a; VIANA; DAL POZ, 1998) A partir de 2006, o PSF configurou-se como estratégia prioritária para reorganização da APS no país, passando a ser denominado Estratégia de Saúde da Família (ESF).

Especificamente em relação à saúde bucal, às tensões relacionadas às diferentes visões da APS adicionam-se dificuldades oriundas do próprio modelo hegemônico de atenção à saúde bucal privatista (NARVAI; FRAZÃO, 2008). Junte-se a isso o escasso interesse do Estado nessa área durante muitas décadas (NARVAI; FRAZÃO, 2008) e a consequente inclusão tardia dos profissionais de saúde bucal no PSF, seis anos depois do início da implantação desse programa no país. (CHAVES et al., 2015)

Apenas em 2004, durante o governo do presidente Luíz Inácio Lula da Silva, as questões referentes à saúde bucal tomaram maior relevância, tendo sido lançada a Política Nacional de Saúde Bucal (PNSB) Brasil Sorridente. (BRASIL, 2004a; CHAVES et al., 2015) Criada para reorganizar o trabalho em saúde bucal nos três níveis de atenção, destacando "o cuidado como eixo de reorientação do modelo, a humanização do processo de trabalho, a corresponsabilização dos serviços e o desenvolvimento de ações voltadas para as linhas do cuidado e condições especiais de vida”. (BRASIL, 2004a, p. 3)

Foi inegável o aumento da oferta de serviços ocorrida com a inclusão das Equipes de Saúde Bucal (ESB) na ESF e com a implementação da PNSB, ainda que as mudanças no modelo de atenção à saúde bucal possam ser questionáveis. No que diz respeito ao quantitativo de equipes e municípios, de 2.200 ESB implantadas em 1.288 municípios em 2001, passou-se a 12.603 equipes em 3.897 (70\%) municípios brasileiros em 2005, com a existência de ESB em 51,3\% 
das Equipes de Saúde da Família (EqSF). (AQUINO et al., 2014) Já em agosto de 2015, contava-se com 22.296 ESB implantadas na modalidade I - CirurgiãoDentista (CD) e Auxiliar de Saúde Bucal (ASB) - e 2.252 na modalidade II - CD, ASB e Técnico de Saúde Bucal (TSB), em 5.025 (90.2\%) municípios brasileiros. (BRASIL, 2015a)

Segundo resultados do inquérito epidemiológico nacional das condições de saúde bucal da população brasileira, realizado em 2010 , 43,5\% das crianças de 12 anos de idade estavam livres de cárie na dentição permanente. O índice CPO-D aos 12 anos (média de dentes cariados, perdidos e restaurados) foi 2,07, o que representa uma redução de $26,2 \%$ quando se compara com esse índice para 2003. (BRASIL, 2004b; BRASIL, 2012b)

O CPO-D em adultos de 35-44 anos passou de 20,1 em 2003 para 16,7 em 2010, redução de 17\%. O componente "perdido" do índice caiu (de 13,23 para 7,48) enquanto o componente "restaurado" aumentou (de 4,22 para 7,33), o que significa que a população adulta dessa faixa de idade, nos últimos sete anos, experimentou menos perdas dentárias relacionadas à cárie e teve maior acesso aos serviços odontológicos para realização de procedimentos restauradores. (BRASIL, 2011)

Apesar dos resultados positivos assinalados, existem diferenças epidemiológicas e iniquidades ao interior do país. O CPO-D aos 12 anos, registrado nas regiões Norte $(3,16)$, Nordeste $(2,63)$ e Centro-Oeste $(2,63)$, foi pior do que aquele observado nas regiões Sudeste $(1,72)$ e Sul $(2,06)$. A participação de dentes restaurados na composição percentual do CPO-D nessa idade é menor na região Nordeste do que na região Sudeste, o que indica que existe um maior ataque da doença associado a menor acesso aos serviços nessa região. (BRASIL, 2012b)

Considerando esse panorama, pretende-se, neste capítulo, descrever o processo histórico de implementação da PNSB no Brasil, em sua interface com as políticas de atenção primária, discutir convergências e dissonâncias entre a política de atenção primária e a política de saúde bucal, sistematizar algumas experiências de implementação da política de saúde bucal no seu componente atenção básica no Brasil e apontar alguns desafios e questões para investigação sobre a política de saúde bucal na atenção básica na atualidade. 


\section{Política de saúde bucal e política de APS: convergências e dissonâncias}

A saúde bucal, tradicionalmente secundarizada pelo Estado brasileiro (CHAVES et al., 2015), apresenta importantes desafios, tanto na ampliação do acesso da população à atenção odontológica quanto na mudança das práticas de saúde bucal, centradas no atendimento clínico individual curativo. (NARVAI; FRAZÃO, 2008) O longo processo de discussões e lutas de poder em torno da temática de saúde bucal teve início em meados da década de 1970, na conjuntura da luta pela redemocratização do país, e no movimento da Reforma Sanitária Brasileira, do qual também fazia parte o Movimento Brasileiro de Renovação Odontológica (MBRO).

O MBRO, apesar de ter um período curto de mobilização (entre 1984-1990), representava ideais progressistas e de esquerda de um grupo de dentistas articulados ao Movimento da Reforma Sanitária Brasileira. Contribuiu para que o ideário da Reforma Sanitária alcançasse os grupos de ativistas da odontologia e os estudantes que se reuniam nos Encontros Científicos de Estudantes de Odontologia (espaços iniciais de politização das questões de saúde bucal). O MBRO foi um espaço de crítica contundente aos programas focalizados verticais vinculados ao Instituto Nacional de Assistência Médica e Previdência Social (Inamps) e ao processo de trabalho odontológico, propondo sua inovação, reorganização do espaço físico do consultório, e a utilização de pessoal auxiliar, questões que seriam incluídas na pauta da $1^{\text {a }}$ Conferência Nacional de Saúde Bucal (CNSB), realizada no mesmo ano na $8^{\text {a }}$ Conferência Nacional de Saúde (CNS). (ZANETTI, 1993)

Em 1986, a $8^{\text {a }}$ CNS reafirmou a saúde como direito dos cidadãos e delineou as bases fundamentais do que seria o SUS. (AQUINO et al, 2014; PAIM et al. 2011) Nesse ano, também o relatório final da $1^{a}$ CNSB criticava o modelo de prática odontológica, caracterizado como ineficaz, ineficiente, monopolizador, de alto custo, de tecnologia densa, iatrogênico, mutilador e elitista, e propunha a inserção do Programa Nacional de Saúde Bucal ao interior do SUS, a estatização dos serviços odontológicos, e a mudança da prática odontológica. (BRASIL, 1986)

De maneira contraditória às conclusões da $1^{\mathrm{a}}$ CNSB e com a Constituição Federal de 1988, no mesmo ano, o Departamento de Odontologia do Inamps criou um programa centralizado e vertical para o controle da cárie dental e o uso de selantes e flúor. (NARVAI, FRAZÃO, 2008; JUNIOR, 2013) De maneira 
similar, em 1989, o MS aprovou a PNSB (NARVAI; FRAZÃO, 2008), duramente criticada pelo MBRO por não seguir as propostas da $1^{\text {a }}$ CNSB e continuar priorizando quase exclusivamente os grupos populacionais em idade escolar. (PALUDETO JUNIOR, 2013) Nos anos seguintes, as ações de saúde bucal focaram-se principalmente na fluoretação da água, dentifrícios e bochechos. (NARVAI; FRAZÃO, 2008)

Em 1993, foi realizada a $9^{\text {a }}$ CNS, e, como parte desta, também realizou-se a $2^{\mathrm{a}} \mathrm{CNSB}$, que em seu relatório final descreve que:

O modelo de saúde bucal vigente no Brasil, caracteriza-se pela limitadíssima capacidade de resposta às necessidades da população brasileira. É ineficaz para intervir na prevalência das doenças bucais que assolam o país, elitista, descoordenado, difuso, individualista, mutilador, iatrogênico, de alto custo, baixo impacto social e desconectado da realidade epidemiológica e social da nação. (BRASIL, 1993, p. 6)

Também nesse relatório, ressaltava-se a necessidade do reconhecimento da saúde bucal como direito de cidadania e de um modelo de atenção à saúde bucal sob as bases da Reforma Sanitária Brasileira. Assim, a atenção primária em saúde bucal deveria ser realizada pela rede básica de saúde de cada município, com equipes de saúde bucal que incluiriam CD, auxiliar, técnico e Agentes Comunitários de Saúde (ACS). Profissionais que, preferencialmente, deveriam ser oriundos da comunidade onde iriam trabalhar e com formação em saúde pública. (BRASIL, 1993)

Novamente, de maneira contraditória às propostas da $2^{\mathrm{a}} \mathrm{CNSB}$, quando se iniciou o PSF, em 1994, os profissionais de saúde bucal não foram reconhecidos como parte deste. Os serviços de saúde bucal continuaram sendo priorizados para a população em idade escolar e atenção de urgência nos adultos. (JUNIOR, 2013; SILVESTRE et al., 2013) Apesar disso, vários municípios brasileiros implementaram seus próprios modelos municipais ou locais de saúde bucal. (JUNIOR, 2013; SILVESTRE et al., 2013) Experiências desse tipo foram desenvolvidas em Curitiba (PR), Sobral (CE), Belo Horizonte (MG), Campinas (SP), Porto Alegre (RS), Santos (SP) e São Paulo (SP), Camaragibe (PE), Distrito Federal e Vitória da Conquista (BA). (MARTELLI, 2010; SILVA, 2011; CHAVES e CRUZ, 2012) Segundo Calado (2002), antes da criação do incentivo financeiro para inclusão das ESB na ESF, em todo Brasil conhecia-se somente 76 experiências de participação desse profissional nas EqSF. 
No ano 2000, houve a publicação dos resultados da Pesquisa Nacional por Amostra de Domicílios (PNAD) sobre acesso e utilização de serviços de saúde que indicou que, em 1998, cerca de 29,6 milhões de brasileiros, ou 19,5\% da população, nunca haviam ido ao dentista. (IBGE,2000) Diante da necessidade de ampliação do acesso da população brasileira às ações de saúde bucal, bem como, da necessidade de melhorar os índices epidemiológicos, no final desse ano, foi estabelecido um incentivo financeiro para reorganizar a atenção à saúde bucal e incluir ESB no PSF. (BALDANI, et al., 2005; RIANI, CHAGAS, SILVESTRE, 2006; SOARES et al., 2011; JUNIOR, 2013)

As ESB integraram-se à ESF a partir da Portaria GM/MS n. ${ }^{\circ} 1.444$, de 28 de dezembro de 2000. (BRASIL, 2000) A inclusão das ESB aconteceria em uma relação de processo de trabalho de duas EqSF para cada uma ESB, que ficaria responsável por aproximadamente 6.900 habitantes. Eram previstas duas modalidades de ESB: na modalidade I, integravam a ESB, um CD e um ASB; e, na modalidade II, incluía-se também o TSB. Em 2003, foram aumentados os incentivos financeiros e permitiu-se a vinculação de uma ESB para cada EqSF. (KORNIS; MAIA; FORTUNA, 2011)

Com o impulso do presidente Lula e o empenho de instituições acadêmicas focadas na saúde coletiva, secretarias de saúde, e outros atores individuais e coletivos, em 2004, foram formuladas as Diretrizes da PNSB Brasil Sorridente. (NARVAI; FRAZÃO, 2008) Essa política orienta-se para a reorganização da atenção a saúde bucal em todos os níveis de atenção, propõe a ampliação e qualificação da atenção básica em saúde bucal, implantação dos Centros de Especialidades Odontológicas (CEO) e Laboratórios Regionais de Próteses Dentárias, fluoretação das águas de abastecimento público, e vigilância em saúde bucal. (BRASIL, 2004a; CHAVES et al., 2015)

O Quadro 1 apresenta uma síntese do processo de implantação da PNSB e o desenvolvimento do modelo de atenção à saúde adotado no Brasil.

Diversos estudos têm evidenciado o impacto da ESF na saúde da população, seja na redução da mortalidade infantil ou das internações hospitalares por causas sensíveis à atenção primária. No caso específico da saúde bucal, ainda que diversos estudos apontem para a ampliação da oferta e utilização de serviços de saúde bucal relacionados à inclusão da ESB na ESF (ANTUNES; NARVAI, 2010; BALDANI et al., 2009; MUNKEVITZ, PELICIONI, 2010), e a PNAD demonstre a redução do percentual de indivíduos que nunca tiveram acesso ao dentista (de $15,9 \%$ em 2003 para $11,7 \%$ em 2008), apenas cerca de $20,3 \%$ das pessoas que 


\begin{tabular}{|c|c|c|c|c|}
\hline Período & $\begin{array}{l}\text { Conjuntura político- } \\
\text { administrativa }\end{array}$ & $\begin{array}{c}\text { Práticas } \\
\text { odontológicas }\end{array}$ & Aspectos chave & $\begin{array}{c}\text { Modelos de atenção à saúde } \\
\text { no Brasil }\end{array}$ \\
\hline 1990 & $\begin{array}{l}\text { Crise política, “impeachment” } \\
\text { do presidente Collor. } \\
\text { Neoliberalismo. } \\
\text { Regulamentação do SUS: Lei } \\
\text { Orgânica da Saúde. } \\
\text { Operacionalização do SUS: } \\
\text { NOB. Descentralização. }\end{array}$ & $\begin{array}{l}\text { Procedimentos } \\
\text { Coletivos (PC) de } \\
\text { saúde bucal. } \\
\text { Implantação do PSF } \\
\text { (1994). }\end{array}$ & $\begin{array}{l}\text { Financiamento de PC pelo MS. } \\
\text { Experiências de inclusão da saúde bucal na } \\
\text { ESF em municípios. }\end{array}$ & $\begin{array}{c}\text { Retrocesso na implementação } \\
\text { do novo modelo, o Modelo } \\
\text { Assistencial. Privatista ganha } \\
\text { força. } \\
\text { O movimento da reforma } \\
\text { sanitária esforça-se em } \\
\text { operacionalizar o SUS. }\end{array}$ \\
\hline $\begin{array}{l}2000- \\
2006\end{array}$ & $\begin{array}{l}\text { Fim do governo Fernando } \\
\text { Henrique Cardoso (2002). } \\
\text { Início do primeiro mandato } \\
\text { governo Lula (2003-2006) }\end{array}$ & $\begin{array}{c}\text { Inclusão da saúde } \\
\text { bucal na ESF } \\
(2000) . \\
\text { Lançamento } \\
\text { da PNSB Brasil } \\
\text { Sorridente (2004) }\end{array}$ & $\begin{array}{l}\text { Início do processo de inclusão por parte dos } \\
\text { municípios. } \\
\text { Expansão da saúde bucal na ESF. } \\
\text { Implantação da rede especializada através dos } \\
\text { CEO. }\end{array}$ & $\begin{array}{l}\text { O SUS busca consolidar- } \\
\text { se com a reorientação da } \\
\text { atenção básica através da ESF, } \\
\text { que se expande rapidamente } \\
\text { pelo país. }\end{array}$ \\
\hline
\end{tabular}




\begin{tabular}{|c|c|c|c|c|}
\hline Período & $\begin{array}{l}\text { Conjuntura político- } \\
\text { administrativa }\end{array}$ & $\begin{array}{c}\text { Práticas } \\
\text { odontológicas }\end{array}$ & Aspectos chave & $\begin{array}{c}\text { Modelos de atenção à saúde } \\
\text { no Brasil }\end{array}$ \\
\hline $\begin{array}{c}2006- \\
2011\end{array}$ & $\begin{array}{l}\text { Segundo mandato do } \\
\text { governo Lula (2007-2010). } \\
\text { Início do governo Dilma } \\
\text { Roussef (2011). }\end{array}$ & $\begin{array}{l}\text { Ampliação do } \\
\text { número de ESB na } \\
\text { proporção um para } \\
\text { um. } \\
\text { Continuidade do } \\
\text { Programa Brasil } \\
\text { Sorridente }\end{array}$ & $\begin{array}{l}\text { Fortalecimento do Brasil Sorridente com } \\
\text { a criação e expansão da rede de centros } \\
\text { especializados (CEO) } \\
\text { Início da qualificação do processo de trabalho } \\
\text { em saúde bucal na lógica da ESF. } \\
\text { Ampliação da fluoretação das águas de } \\
\text { abastecimento público. } \\
\text { Avanços na implantação e qualificação da rede } \\
\text { de saúde bucal do SUS? } \\
\text { IV Conferência Nacional de Saúde Bucal? }\end{array}$ & $\begin{array}{l}\text { ESF configura-se como } \\
\text { modelo assistencial } \\
\text { reorganizador da atenção } \\
\text { primária. } \\
\text { Fortalecimento do SUS. }\end{array}$ \\
\hline $\begin{array}{l}2012- \\
2015\end{array}$ & $\begin{array}{l}\text { Primeiro mandato Dilma } \\
\text { Roussef (2011-2014). } \\
\text { Segundo mandato Dilma } \\
\text { Roussef (2015). } \\
\text { Crise ética, política e } \\
\text { econômica. }\end{array}$ & $\begin{array}{l}\text { Redes de Atenção à } \\
\text { Saúde Bucal - Linhas } \\
\text { de Cuidado } \\
\text { - Rede Cegonha } \\
\text { - Rede de Cuidados } \\
\text { à Pessoa com } \\
\text { Deficiência. }\end{array}$ & $\begin{array}{c}\text { PMAQ - AB } \\
\text { PMAQ - CEO } \\
\text { e-SUS } \\
\text { GraduaCEO }\end{array}$ & $\begin{array}{l}\text { Fragilização da gestão do SUS: } \\
\text { concessão da administração e } \\
\text { gerenciamento do SUS desde } \\
\text { a atenção primária à terciária } \\
\text { às Organizações Sociais de } \\
\text { Saúde, à Empresa Brasileira de } \\
\text { Serviços Hospitalares, criando } \\
\text { um cenário de terceirização } \\
\text { da saúde. }\end{array}$ \\
\hline
\end{tabular}

Fonte: adaptado de Carcereri (2005); Narvai e Carcereri (2011). 
tiveram atendimento nas últimas duas semanas devido a problema odontológico foram atendidas na rede pública (unidade básica de saúde ou centro de saúde). (IBGE, 2008) Ou seja, esse aumento na oferta e utilização dos serviços não se deu necessariamente no setor público, nem implica necessariamente em efetivas mudanças de prática ou reversão do modelo de atenção.

Várias pesquisas têm apontado que as ESB na ESF apresentam dificuldades importantes em tornar efetiva a mudança do modelo de atenção em saúde bucal. (MARTELLI et al., 2008; PEREIRA et al, 2012; REIS; SCHERER; CARCERERI, 2015; SOUZA; RONCALLI, 2007)

Estudos empíricos verificaram que a organização do processo de trabalho da ESB é realizada à parte dos outros participantes da ESF, bem como a organização da oferta de serviços de saúde bucal acontece sem conexão com a saúde geral. (FACCIN; SEBOLD; CARCERERI, 2010; PIMENTEL et al, 2010; FARIAS; SAMPAIO, 2011; PADULA; AGUILAR-DA-SILVA; 2014) Existe uma reprodução das tradicionais atividades coletivas do CD nas escolas, e existem poucos espaços para o trabalho em equipe. (FACCIN; SEBOLD; CARCERERI; 2010; PIMENTEL et al, 2010; PADULA, AGUILAR-DA-SILVA, 2014) Dessa maneira, a ESB e a EqSF parecem funcionar de maneira diferenciada.

As pesquisas também apontam que somente se observa integração na disponibilidade para responder à demanda imediata, nos encaminhamentos internos (NASCIMENTO et al., 2009; FACCIN, SEBOLD, CARCERERI, 2010; FARIAS, SAMPAIO, 2011), ou em atividades pontuais de trabalho em conjunto durante campanhas de vacinação (PIMENTEL et al., 2010), atividades de educação e prevenção em saúde bucal nas escolas, atendimento a pacientes de grupos programáticos (MATTOS et al., 2014), e organização da oferta baseada nas linhas de cuidado, ainda que o atendimento baseado na demanda espontânea seja predominante. (TAVARES et al., 2013)

Atividades como as reuniões de equipe e a visita domiciliar em conjunto com a EqSF não fazem parte do processo de trabalho habitual do $\mathrm{CD}$, por isso sua participação nelas é mínima. As reuniões de equipe não têm a periodicidade esperada (uma semana). Em muitos casos, ocorrem mensalmente, sem periodicidade definida, ou não ocorrem. (BALDANI et al, 2005; COSTA, ARAUJO, 2013; FACCIN; SEBOLD; CARCERERI, 2010; FARIAS; SAMPAIO, 2011; MOURA et al., 2013) As visitas domiciliares têm periodicidade variada, dependente da importância que cada equipe considere, e da disponibilidade de meios de transporte. (COSTA e ARAUJO, 2013; MOURA et al., 2013) 
Algumas pesquisas têm identificado situações onde os CD referem que existe conexão entre a ESB e a ESF (BALDANI et al., 2005), que sempre participam das reuniões de equipe e que sempre desenvolvem ações com a equipe de saúde da família. (SOUZA; RONCALLI, 2007) Ainda assim, os CD apontaram que elaboram e desenvolvem os programas de ação em saúde bucal sozinhos, sem suporte técnico, administrativo ou financeiro, pelo que a realização dessas atividades fica dependente de cada $\mathrm{CD}$, da sua permanência na ESF, no município, e da vontade e estímulo que ele tenha para o desenvolvimento delas. (SOUZA; RONCALLI, 2007) Assim, observa-se que existe um bom relacionamento pessoal, mas não existe uma adequada articulação dos saberes e conhecimentos para gerar uma intervenção conjunta. (FACCIN; SEBOLD; CARCERERI, 2010)

Outros estudos que têm buscado avaliar a saúde bucal na ESF a partir da expansão e do desempenho das ESB/ESF no nível estadual, através da análise de dados provenientes dos sistemas de informação de saúde (BALDANI et al., 2005; SILVA et al., 2011 PALACIO et al., 2014; PIMENTEL et al., 2014); no âmbito municipal, buscam identificar os nós críticos relacionados à implementação da estratégia a partir do ponto de vista dos usuários (ANDRADE: FERREIRA, 2006; EMMI: BARROSO, 2008), gestores (MARTELLI et al., 2008), e gestores e trabalhadores. (LOURENÇO et al., 2009; MATTOS et al., 2014; SOUZA; RONCALLI, 2007) Além disso, os estudos contemplam aspectos relacionados ao acesso e/ou utilização dos serviços de saúde bucal em áreas cobertas pela ESF. (SANTOS et al., 2007; CHAVES et al., 2012; SOARES et al., 2013; OLIVEIRA et al., 2014)

Os estudos de base populacional (CHAVES et al., 2012; OLIVEIRA et al., 2014; PEREIRA et al., 2009; PEREIRA et al., 2012; ROCHA, GOES, 2008; SOARES et al., 2013) têm evidenciado diferentes resultados com relação à inclusão da ESB/ESF nos municípios.

Em municípios de 50 mil a 100 mil habitantes da Bahia, com 100\% de cobertura da ESF, a utilização de serviços públicos na APS variou entre 23,2\% e 30\%. (CHAVES et al., 2012; SOARES et al., 2013) Em áreas cobertas pela ESF no município de Olinda (PE), verificou-se que $18,9 \%$ da população acima de 18 anos havia utilizado os serviços de saúde bucal da ESF. (OLIVEIRA et al., 2014)

Apenas três estudos buscaram comparar o desempenho dos serviços de saúde bucal em áreas cobertas e não cobertas por ESB/ESF, a fim de identificar as diferenças relacionadas à implantação dessa estratégia. (ROCHA; GOES, 2008; PEREIRA et al., 2009; PEREIRA et al., 2012) Nestes, não foi observada dife- 
rença de acesso aos serviços de saúde bucal entre residentes de áreas cobertas por ESB/ESF ou não cobertas (ROCHA; GOES, 2008), ou observou-se maior acesso a assistência odontológica em residentes de áreas cobertas pelo Programa de Agentes Comunitários de Saúde (PACS) ou ESF sem ESB, mas com CD. (PEREIRA et al., 2009) Estudo envolvendo 12 municípios com mais de 100 mil habitantes do Nordeste do Brasil não confirmou diferenças no acesso aos serviços odontológicos entre áreas cobertas e não cobertas por ESB/ESF, indicando a necessidade de investigar os fatores que levaram a esses resultados. (PEREIRA et al., 2012) Nesse sentido, é fundamental analisar o desenvolvimento da política de saúde bucal nos municípios, compreendendo o contexto político, cultural e social de sua implementação em cada local. Destaca-se a importância de relativizar os resultados considerando a implantação do novo modelo em cada município estudado. O município segue os pressupostos da ESF? Pode ser considerado um caso, um exemplo de implantação da política?

Nessa perspectiva, apresentaremos a seguir resultados de três estudos de caso realizados, dois em municípios do estado da Bahia (Salvador e Vitória da Conquista), e o terceiro em Florianópolis, Santa Catarina, que analisaram a implantação de equipes de saúde bucal como parte da ESF. Apesar de partirem de abordagens metodológicas diferentes, os estudos de caso dessas três experiências municipais trazem elementos para a discussão dos nós críticos sobre a implementação da política de saúde bucal no âmbito da atençãoo primária à saúde.

\section{Inclusão das ESB/ESF em Salvador e Vitória da Conquista, Bahia}

O ensaio comunitário realizado por Pereira e colaboradores (2012) avaliou agravos de saúde bucal (morbidade dentária autorreferida e prevalência de dor de origem dentária), acesso a serviço odontológico (consulta ao dentista no último ano), cobertura de ações curativo-reparadoras (tratamento de dor de origem dentária, tratamento restaurador e exodontia) e cobertura de ações preventivas (acesso a ações preventivas individuais e acesso a ações preventivas coletivas) em áreas cobertas e não cobertas por ESB/ESF em 12 municípios com mais de 100 mil habitantes do Nordeste do Brasil. Em cada município, foram sorteados respectivamente 10 setores censitários de áreas cobertas por ESB/ESF, que foram intencionalmente pareados com setores censitários não cobertos, identificados por proximidade geográfica e condição socioeconômica, sendo excluídos setores censitários que se localizavam em áreas parcialmente cobertas. 
Os dois municípios do estado da Bahia incluídos nesse estudo (Pereira et al., 2012), Salvador e Vitória da Conquista, tiveram desempenhos divergentes com relação aos indicadores de saúde bucal selecionados, em 2007, ano de realização da pesquisa de campo. Compreende-se que essas diferenças relacionem-se aos diferentes processos históricos de implementação das ações e políticas de saúde bucal nos municípios, bem como as prioridades municipais, refletindo em diferentes resultados sobre o estado de saúde da população, o acesso aos serviços de saúde e em termos de conhecimento e comportamentos derivados das práticas desenvolvidas.

Desse modo, é importante analisar os resultados dos indicadores de saúde bucal, à luz do processo histórico ${ }^{1}$ de implementação e a reorganização das práticas das ações de saúde bucal em ambos os municípios.

\section{Salvador}

No período de 1997 a 2004, Salvador teve continuidade político-administrativa, com a permanência de um mesmo grupo político na gestão municipal, estabelecendo-se para o período de 2005 a 2012 a gestão por outro grupo político. A proposta inicial de implantação da ESF no município era alcançar 100\% de cobertura no distrito sanitário de maior vulnerabilidade socioeconômica, o Subúrbio Ferroviário. Essa estratégia foi abandonada ao longo do processo de implementação da ESF, com a implantação de unidades em outras áreas da cidade, formando ilhas de áreas adstritas, cercadas por um mar de grandes áreas não cobertas, dificultando a implementação da adstrição de clientela. A implantação da ESB/ESF iniciou-se em 2001, logo após a instituição do incentivo financeiro com essa finalidade pelo MS, com quatro ESB/ESF para 14 EqSF, quando a cobertura da ESF era de 1,94\% da população. Em 2007, a cobertura da ESF chegou a 14,62\%, com 83 ESB/ESF para 115 EqSF (Tabela 1).

Soares e Paim (2011) identificaram como barreiras à implementação da política de saúde bucal no município, no período de 2004 a 2007, o contexto de ausência de autonomia financeira da secretaria municipal de saúde, descompromisso do prefeito com a política de saúde e a precarização das relações de trabalho, bem como a ausência de um projeto consistente de saúde bucal.

\footnotetext{
$1 \quad$ Resultados parciais do projeto "A gênese da política de saúde bucal nos âmbitos nacional e municipal”, edital Fapesb n. 017/2013. Apoio a projetos de pesquisa para Jovem Cientista no Estado da Bahia, T.O. n. JCBOo4O/2013, coordenado pela profa. Sandra Garrido de Barros.
} 


\begin{tabular}{|c|c|c|c|c|c|c|c|c|}
\hline $\begin{array}{l}\text { Município } \\
\text { (ano de } \\
\text { implantação } \\
\text { ESF) }\end{array}$ & Indicadores & 2001 & 2002 & 2003 & 2004 & 2005 & 2006 & 2007 \\
\hline \multirow{5}{*}{$\begin{array}{l}\text { Salvador } \\
(2000)\end{array}$} & População & 2.485 .702 & 2.485 .702 & 2.520 .504 & 2.556 .429 & 2.556 .429 & 2.673 .560 & 2.714 .018 \\
\hline & EqSF impl. (n) & 14 & 20 & 31 & 81 & 110 & 115 & 115 \\
\hline & ESB impl. (n) & 4 & 7 & 11 & 62 & 78 & 85 & 83 \\
\hline & Cob. Est. ESF (\%) & 1,94 & 2,78 & 4,24 & 10,93 & 14,84 & 14,84 & 14,62 \\
\hline & Cob. Est. ACS (\%) & 20,77 & 22,65 & 24,30 & 29,85 & 35,45 & 35,77 & 31,61 \\
\hline \multirow{5}{*}{$\begin{array}{l}\text { Vitória da } \\
\text { Conquista } \\
(1998)\end{array}$} & População & 267.189 & 267.189 & 270.364 & 274.618 & 274.618 & 286.575 & 290.690 \\
\hline & EqSF impl. & 30 & 31 & 32 & 36 & 37 & 37 & 37 \\
\hline & ESB impl. & 15 & 15 & 15 & 26 & 27 & 27 & 27 \\
\hline & Cob. Est. ESF (\%) & 38,74 & 40,03 & 40,83 & 45,23 & 46,48 & 44,54 & 43,91 \\
\hline & Cob. Est. ACS (\%) & 81,56 & 93,61 & 95,92 & 97,78 & 96,11 & 87,88 & 85,45 \\
\hline
\end{tabular}

Fonte: Ministério da Saúde/Secretaria de Atenção à Saúde/Departamento de Atenção Básica, outubro, 2015

Em 2007, no estudo conduzido por Pereira e colaboradores (2012), a capital do estado não apresentou diferença significativa entre áreas cobertas e não cobertas com relação à necessidade percebida de assistência odontológica $(\mathrm{p}=0,34)$ e dor de origem dentária $(\mathrm{p}=0,74)$. Entretanto, foi o município com maior necessidade acumulada de tratamento $(74,7 \%$ dos indivíduos de áreas cobertas e $76,2 \%$ de áreas não cobertas referiram necessidade de tratamento odontológico) dentre os 12 municípios do Nordeste analisados (Tabela 2).

O município apresentou impacto positivo da implementação da ESB/ESF com relação a utilização de serviço odontológico, oito vezes maior em áreas cobertas ( $\mathrm{p}<0,01$; RP=0,43; IC 95\%: ०,43-0,50), cobertura de ações clínicas individuais, como procedimento restaurador ( $\mathrm{p}<0,01 ; \mathrm{RP}=0,0,51$; IC 95\%: ०,43-0,50) e tratamento de dor de origem dentária ( $\mathrm{p}<0,00$; $\mathrm{RP}=0,0,65$; IC 95\%: ०,59-0,72) e ações preventivas individuais ( $\mathrm{p}<0, \mathrm{O} 1 ; \mathrm{RP}=0,47$; IC 95\%: $\circ, 43-0,51)$ e coletivas ( $\mathrm{p}<0,01 ; \mathrm{RP}=0,59 ;$ IC 95\%: ०,56-0,62) (Tabela 2).

Pode-se inferir, portanto, que, no município de Salvador, a inclusão das ESB/ ESF proporcionou ampliação significativa da rede de serviços odontológicos na esfera pública, ainda que alcançando uma baixa cobertura populacional. 
A inclusão das ESB/ESF significou maior acesso a serviços de saúde bucal nas áreas cobertas, seja relacionado a ações clínicas individuais, seja com relação a procedimentos preventivos individuais e coletivos. Para todos os tipos de serviços analisados, a probabilidade de um morador de área coberta por ESB/ESF ser atendido na sua unidade de referência foi maior que em áreas não cobertas.

Tabela 2 - Agravos de saúde bucal, acesso a serviços odontológicos na unidade, cobertura de ações clínicas individuais e cobertura de ações preventivas em áreas cobertas e não cobertas por ESB/PSF em Salvador (SSA) e Vitória da Conquista (VdC), Bahia, 2007 (continua)

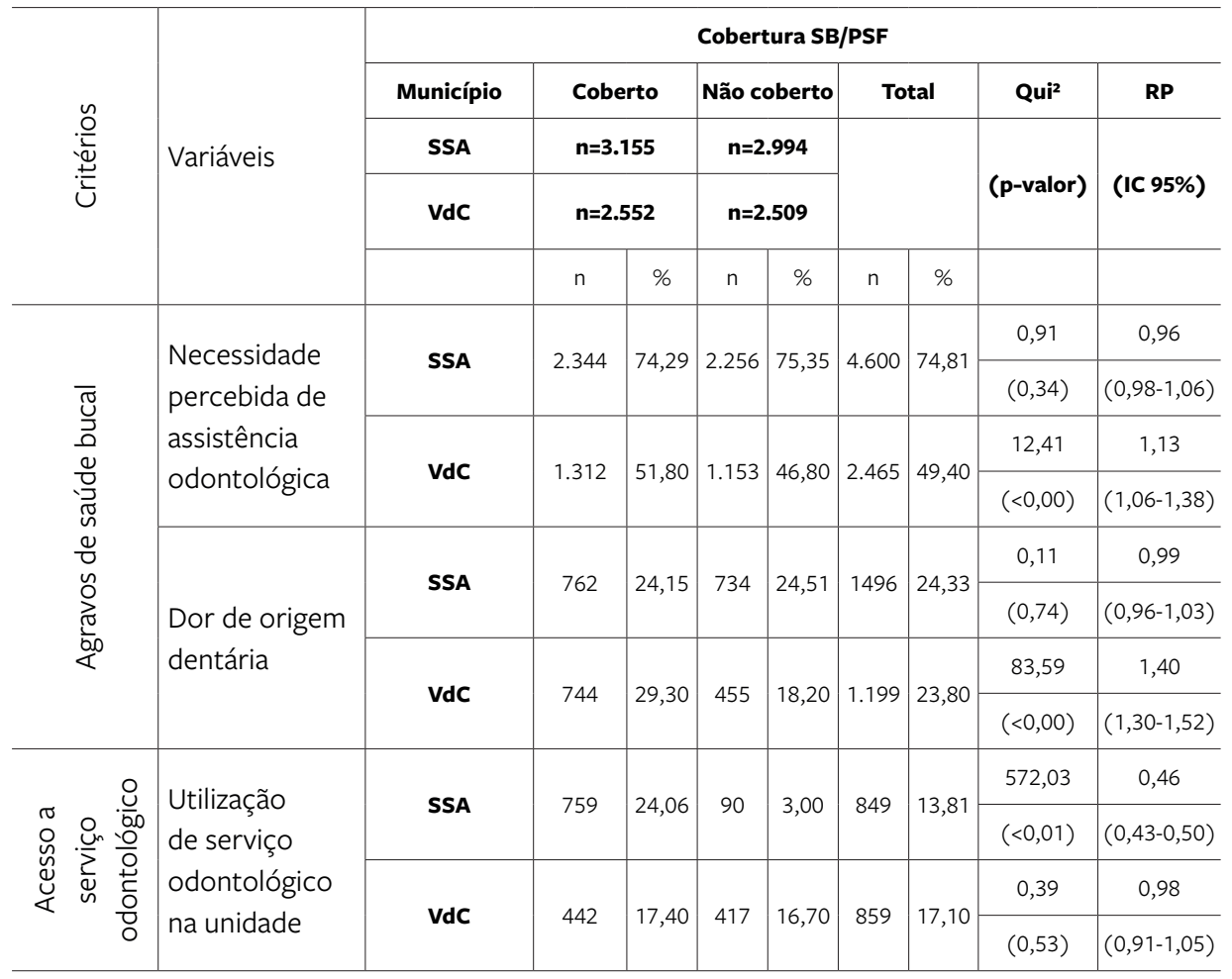


Tabela 2 - Agravos de saúde bucal, acesso a serviços odontológicos na unidade, cobertura de ações clínicas individuais e cobertura de ações preventivas em áreas cobertas e não cobertas por ESB/PSF em Salvador (SSA) e Vitória da Conquista (VdC), Bahia, 2007

\begin{tabular}{|c|c|c|c|c|c|c|c|c|c|c|}
\hline \multirow{5}{*}{ 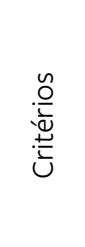 } & \multirow{5}{*}{ Variáveis } & \multicolumn{9}{|c|}{ Cobertura SB/PSF } \\
\hline & & Município & \multicolumn{2}{|c|}{ Coberto } & \multicolumn{2}{|c|}{ Não coberto } & \multicolumn{2}{|c|}{ Total } & Qui $^{2}$ & $\mathbf{R P}$ \\
\hline & & SSA & \multicolumn{2}{|c|}{$n=3.155$} & \multicolumn{2}{|c|}{$\mathrm{n}=2.994$} & & & & \multirow[t]{2}{*}{ (IC 95\%) } \\
\hline & & VdC & \multicolumn{2}{|c|}{$\mathrm{n}=\mathbf{2 . 5 5 2}$} & \multicolumn{2}{|c|}{$n=2.509$} & & & & \\
\hline & & & $n$ & $\%$ & $n$ & $\%$ & $n$ & $\%$ & & \\
\hline \multirow{8}{*}{ 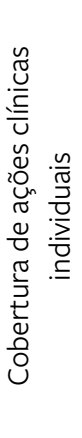 } & \multirow{4}{*}{$\begin{array}{l}\text { Realização de } \\
\text { procedimento } \\
\text { restaurador }\end{array}$} & \multirow{2}{*}{ SSA } & \multirow{2}{*}{271} & \multirow{2}{*}{8,59} & \multirow{2}{*}{37} & \multirow{2}{*}{1,24} & \multirow{2}{*}{308} & \multirow{2}{*}{5,01} & 174,57 & 0,51 \\
\hline & & & & & & & & & $(<0,01)$ & $(0,45-0,57)$ \\
\hline & & \multirow{2}{*}{ VdC } & \multirow{2}{*}{284} & \multirow{2}{*}{11,20} & \multirow{2}{*}{340} & \multirow{2}{*}{13,60} & \multirow{2}{*}{624} & \multirow{2}{*}{12,40} & 6,65 & 1,12 \\
\hline & & & & & & & & & $(0,01)$ & $(1,03-1,23)$ \\
\hline & \multirow{4}{*}{$\begin{array}{l}\text { Tratamento de } \\
\text { dor de origem } \\
\text { dentária }\end{array}$} & \multirow{2}{*}{ SSA } & \multirow{2}{*}{231} & \multirow{2}{*}{30,31} & \multirow{2}{*}{99} & \multirow{2}{*}{13,49} & & & 60,60 & 0,65 \\
\hline & & & & & & & על & $2<, 00$ & $(<0,00)$ & $(0,59-0,72)$ \\
\hline & & VdC & 189 & 2560 & 180 & 3960 & 369 & 3090 & 25,90 & 1,31 \\
\hline & & & $10 \%$ & 20,00 & 100 & (2), 390 & & 0,0 & $(0,00)$ & $(1,17-1,46)$ \\
\hline$\tilde{N}$ & & $\operatorname{csn}$ & 626 & 1084 & 71 & & & & 459,37 & 0,47 \\
\hline 美 & Ações & הת הכת & $0<0$ & 1,04 & 74 & $2,4 \prime$ & tou & (11,כ0 & $(<0,01)$ & $(0,43-0,51)$ \\
\hline む) & individuais & Vac & 277 & 1000 & 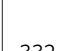 & 20 & & & 6,54 & 1,12 \\
\hline ข్ & & vac & $27 \pi$ & 10,90 & 332 & 13,30 & 609 & 12,10 & $(0,01)$ & $(1,03-1,23)$ \\
\hline $\begin{array}{c}\tilde{0} \\
0 \\
1\end{array}$ & & $\csc \theta_{1}$ & 704 & 240 & 100 & 20 & רד0 & & 398,06 & 0,59 \\
\hline$\frac{\sigma}{3}$ & P. & ה מכת & 104 & 24,05 & 100 & $0, \angle 0$ & PIL & $|12,8|$ & $(<0,01)$ & $(0,56-0,62)$ \\
\hline $\begin{array}{l}\frac{1}{d} \\
\text { Oे }\end{array}$ & rarestias & Vdc & 277 & 10 & 363 & 1450 & 640 & 1270 & 14,63 & 1,04 \\
\hline U & & ( & 211 & 10,00 & (50) & 14,30 & 040 & 12,10 & $(<0,00)$ & $(1,02-1,06)$ \\
\hline
\end{tabular}

Fonte: (UFRN), financiado pelo edital MCT-CNPq / MS-DAB/SAS - No 49/2005.

\section{Vitória da Conquista}

Vitória da Conquista apresentava continuidade político-administrativa desde 1997, com manutenção do mesmo grupo político na gestão municipal até 2015. A reorganização da APS do município a partir da ESF foi uma decisão política dos gestores municipais. A ESF foi adotada como substitutiva, mas não como única estratégia no município, que manteve unidades básicas convencionais com equipes do PACS. Foram seguidas, contudo, algumas diretrizes para 
todas as unidades do município, a saber: mapeamento e territorialização; definição de áreas de abrangência e clientela adstrita; APS como porta de entrada do sistema de saúde.

O município tem um histórico de implantação de ESB iniciado em 1998, sendo um dos 76 municípios do país que incluiu a saúde bucal na ESF antes da criação do incentivo financeiro estabelecido no final de 2000. Já em 2001, tinha 14 ESB/ESF para 30 EqSF, com uma cobertura da ESF de 8,74\%. Em 2007, o município contava com 37 ESB/ESF para 37 EqSF, alcançando 43,91\% de cobertura da ESF. A cobertura estimada de ACS no município (áreas cobertas e não cobertas pela ESF) foi superior a $85 \%$ durante seis anos no período de 2001 a 2007 e a cobertura da ESF esteve acima de $40 \%$ durante todo o período (Tabela 1). O município adota a adstrição de clientela também nas unidades básicas convencionais, sendo que algumas dessas funcionavam em sistema de três turnos de atendimento, com funcionamento noturno, o que não ocorre nas unidades de saúde da família.

No estudo conduzido por Pereira e colaboradores (2012), Vitória da Conquista apresentou maior necessidade de assistência odontológica percebida e maior percentual de dor de origem dentária nos moradores de áreas cobertas por ESB/ESF. Não houve diferenças entre áreas cobertas e não cobertas com relação à utilização de serviços odontológicos, mas para a cobertura de ações clínicas individuais e ações preventivas individuais e coletivas, as maiores coberturas foram observadas nas áreas não cobertas (Tabela 2). Há que se destacar que o município apresentou os menores percentuais de necessidade de tratamento em ambos os modelos estudados entre os 12 municípios analisados por Pereira e colaboradores (2012).

No município de Vitória da Conquista, as áreas cobertas não apresentaram melhor desempenho que as áreas não cobertas, contudo, há que se destacar que todas as unidades básicas convencionais tinham área de abrangência definida, cadastramento familiar e clientela adstrita, sendo que algumas funcionavam em regime de três turnos. Ou seja, muito provavelmente o melhor resultado nos indicadores de acesso e utilização observados nas áreas não cobertas estão relacionados a esses fatos. Os resultados observados no município corroboram com os achados de Pereira e colaboradores (2009) no município de Natal, Rio Grande do Norte, onde também foi observado maior acesso a serviços odontológicos em áreas cobertas por ACS ou ESF sem ESB, mas com CD. 


\section{Implementação da política de saúde bucal no componente atenção básica em Florianópolis, Santa Catarina}

O caso de Florianópolis ocorre em um contexto de forte apoio da gestão estadual. No estado de Santa Catarina, a implantação do PSF iniciou-se em 1994 e ampliou-se por meio dos convênios firmados entre o MS e os municípios. Os primeiros dados do programa surgiram a partir da Portaria n. ${ }^{\circ}$ 1886/GM, de 18 de dezembro de 1997 (BRASIL, 1997b), que vinculou os recursos financeiros à alimentação do Sistema de Informação da Atenção Básica. (HENRIQUE; CAL$\mathrm{VO}, 2008)$

Com forte apoio da Secretaria de Estado de Saúde, as primeiras cidades catarinenses a contarem com as EqSF foram Ascurra, Chapecó e Blumenau. (SANTA CATARINA, 2009) Em 2009, 15 anos após a implantação, o estado de Santa Catarina tornou-se o primeiro estado do país a contar com a ESF em todos os municípios a partir do credenciamento, junto ao MS, de EqSF em Mirim Doce, única cidade que ainda não oferecia o serviço.

Mesmo tendo a PNAB como norteadora, as condições e características de implantação do novo modelo nos diferentes municípios foram heterogêneas, variabilidade que, na prática, configurou a expressão concreta dos contextos e momentos históricos específicos de cada experiência de implantação.

Na capital, Florianópolis, observou-se particularidades e um atraso relativo na implantação da ESF em comparação a outros municípios do estado de porte semelhante. As discussões iniciaram-se em 1994 e, em 1996, foram implantadas seis EqSF cobrindo quatro áreas de abrangência, aumentando esse número para 25 áreas no período de 1997/2000. (CONILL, 2002) As ESB/ESF foram instituídas no município a partir de agosto de 2004. Essa inserção tardia das ESB junto às EqSF, trouxe como consequência uma diferença significativa na cobertura populacional das equipes, ilustrada no Quadro 2. Além disso, o foco das ESB estava nas ações direcionadas aos escolares, nas demandas clínicas curativas dos usuários e também na integração desses profissionais às EqSF que já atuavam nas Unidades Básicas de Saúde (UBS). (FACCIN; SEBOLD, 2006)

Em 2006, dois anos após a inserção das ESB, observou-se que as práticas das ESB caracterizavam-se por realização de ações puramente clínicas, de cunho individual, sendo a inserção ao trabalho multiprofissional, pautado na integralidade do cuidado, o maior desafio. (FACCIN; SEBOLD, 2006) Questões como a falta de capacitação/formação para atuar na ESF, incompreensão do profissional como membro de uma equipe, manutenção das práticas tradicio- 
nais no trabalho preventivo com foco nos escolares, excesso de população na área adstrita, falta de adequação do ambiente de trabalho (vários dentistas em um mesmo espaço), escassez de recursos humanos - principalmente auxiliares, dificuldades de referenciamento ao nível secundário, foram relatados como pontos cruciais, os quais deveriam sofrer intervenções para que ocorresse a transformação das práticas (Quadro 2).

\section{Quadro 2 - Caracterização do processo de implantação ESF e ESB em Florianópolis, de 2002 a 2014}

\begin{tabular}{|c|c|c|c|c|c|c|c|c|}
\hline $\begin{array}{l}\text { Dados e } \\
\text { características }\end{array}$ & 2002 & 2005 & 2006 & 2007 & 2008 & 2010 & 2012 & 2014 \\
\hline $\begin{array}{l}\text { População } \\
\text { municipal }\end{array}$ & 360.603 & 396.778 & 406.564 & 416.267 & 402.346 & 402.346 & 427.298 & 433.158 \\
\hline $\begin{array}{l}\text { Cobertura } \\
\text { Populacional PSF/ } \\
\text { ESF }\end{array}$ & $41,1 \% \%$ & $61,7 \%$ & $67,8 \%$ & $71,3 \%$ & $77,6 \%$ & $84 \%$ & $92,04 \%$ & $94,78 \%$ \\
\hline $\begin{array}{l}\text { No de ESB } \\
\text { implantadas }\end{array}$ & 42 & 66 & 78 & 84 & 87 & 98 & 114 & 119 \\
\hline $\begin{array}{l}\text { NO ESB } \\
\text { implantadas }\end{array}$ & 0 & 10 & 9 & 25 & 29 & 39 & 59 & 65 \\
\hline $\begin{array}{l}\text { Cobertura } \\
\text { Populacional ESB }\end{array}$ & 0 & $9,2 \%$ & $7,8 \%$ & $21,13 \%$ & $25,66 \%$ & $33,41 \%$ & $47,66 \%$ & $51 \%$ \\
\hline $\begin{array}{l}\text { No de Centros de } \\
\text { Saúde }\end{array}$ & 47 & 48 & 48 & 48 & 48 & 48 & 49 & 49 \\
\hline \multirow{3}{*}{$\begin{array}{l}\text { Presença } \\
\text { de práticas } \\
\text { inovadoras na } \\
\text { Rede de Atenção } \\
\text { à Saúde (RAS) }\end{array}$} & \multicolumn{8}{|c|}{$\begin{array}{l}\text { Centro de Saúde (CS) campo de prática para graduação e pós-graduação (Residência em Saúde } \\
\qquad \text { da Família) }\end{array}$} \\
\hline & & & & \multicolumn{5}{|c|}{ Informatização Sistema } \\
\hline & & & & & & \multicolumn{3}{|c|}{$\begin{array}{l}\text { Núcleo de Apoio à Saúde da } \\
\text { Família } \\
\text { Complexo regulador }\end{array}$} \\
\hline $\begin{array}{l}\text { Habilitação em } \\
\text { gestão }\end{array}$ & $\begin{array}{r}\text { Gestão } \\
\text { pela } N \\
\text { Assi }\end{array}$ & $\begin{array}{l}\text { na da ater } \\
\text { ma Opera } \\
\text { ência à Sa }\end{array}$ & $\begin{array}{l}\text { o básica } \\
\text { nal da } \\
02\end{array}$ & & Termo de & to pela Sai & de Gestão & \\
\hline $\begin{array}{l}\text { Índice de } \\
\text { Desenvolvimento } \\
\text { Humano***}\end{array}$ & 0,881 & - & 0,875 & 0,875 & 0,875 & 0,847 & 0,847 & 0,847 \\
\hline
\end{tabular}

Fonte: adaptado de Sisson e colaboradores (2011) 
Tal pesquisa registrou insuficiente processo de discussão sobre as mudanças no processo de trabalho em saúde bucal carreadas pelo então PSF. Embora se tratando da introdução de um novo modelo de atenção, o espaço de discussão limitou-se ao treinamento introdutório para atuação no Programa. Assim, a inserção da ESB findou representando, naquele momento, simplesmente uma mudança contratual.

Em 2007, três anos após a implantação das ESB, seguindo os moldes Política Nacioanl da Atenção Básica (PNAB), foi aprovada a Política Municipal de Atenção Básica (PMAB) (Portaria/SS/GAB/ n. ${ }^{\circ}$ 283), que estabeleceu diretrizes e normas para a organização da atenção básica baseada na ESF.

Observou-se, então, uma nova postura da gestão municipal com relação à atenção básica, estabelecendo normativas que possibilitaram operacionalizar a ESF no município. Questões como definição de área adstrita com população de até 4 mil habitantes por EqSF, podendo essa ser reduzida em caso de áreas com interesse social; incentivo ao planejamento ascendente; definição do processo de trabalho pautado na territorialização, no acolhimento, no cadastramento domiciliar, além de proposição de atividades mínimas a serem oferecidas pelas UBS. Vale destacar ainda que o município adotou a integração ensino-serviço como eixo norteador, incluindo a supervisão de alunos de graduação como parte do processo de trabalho dos profissionais.

A partir dessa Portaria, foram regulamentadas as reuniões de área e as reuniões de planejamento das UBS como um todo, com normatização de carga horária e periodicidade. Dessa forma, foram ofertados aos profissionais momentos de encontro semanais e mensais.

Uma das características do processo de trabalho apontada pelo MS é o trabalho interdisciplinar e em equipe, promovendo a integração de profissionais com diferentes formações. (BRASIL, 2011)

Segundo Paim (2002), se o enfoque interdisciplinar for incorporado na formulação de políticas públicas e na organização de serviços de saúde, pode contribuir para mudar sua formação, desde a graduação. Destaca-se que o trabalho interdisciplinar multiprofissional e em equipe pode propiciar a retroalimentação no cuidado dos usuários e pode contribuir assim estrategicamente com a integralidade da atenção. Porém, é necessário manter as discussões em torno da interdisciplinaridade, vinculando a atual política de saúde, norteada pelo princípio da integralidade, com o exercício profissional, cujos modelos ainda permanecem conectados às práticas que, pendularmente, oscilam entre 
o uni e o multidisciplinar, indicando uma execução de disciplinas desprovidas de objetivos comuns sem aproximação ou cooperação. (MENDES; LEWGOY; SILVEIRA, 2008)

Após a publicação das políticas, uma nova pesquisa realizada no município por Ferreira (2010) teve como foco a integralidade do cuidado. Essa pesquisa evidenciou uma apropriação pelas EqSF e ESB do processo de trabalho como apontado na PMAB, principalmente pela introdução de novas práticas, denominadas pelo autor de "práticas sociais no cuidado da saúde". Foram consideradas práticas sociais o levantamento das necessidades da comunidade e posterior priorização gerada a partir de discussões entre a equipe, a realização de visita domiciliar, vinculação com comunidade e usuários, acolhimento e humanização do trabalho com foco na promoção da saúde.

Essa incorporação não foi homogênea mesmo dentro de uma mesma equipe, o que constituiu entraves, tanto para mudanças no processo de trabalho quanto para a implementação de um novo modelo de atenção. Parte dos entraves deve-se à formação, fragmentada e centrada nas especialidades, às dificuldades no acesso, à assistência pelos usuários, à carência de recursos materiais e de pessoal para atividades extramuros, ao conflito de poderes na indefinição do papel de cada profissional nas equipes, o que poderia influenciar na eficiência da equipe, à resistência em querer aprender o "algo mais", ir além "do céu da boca". (FERREIRA, 2009)

Em 2015, Florianópolis atingiu 100\% de cobertura, conquistando nacionalmente o título de melhor capital em cobertura da ESF. Para a saúde bucal, no entanto, a cobertura é de $54 \%$, demonstrando o descompasso entre a PNAB e a PNSB no município. (BRASIL, 2015b) Apesar do contexto de defasagem de cobertura de ESB em relação às EqSF, a capital destaca-se em outros quesitos, como, por exemplo, a priorização de contratação de profissionais por concurso, a carga horária de trabalho de 40 horas e a estrutura das UBS. Tal desempenho lhe valeu, em 2015, o quarto lugar no Prêmio Brasil Sorridente de Boas Práticas em Saúde Bucal. (CONSELHO REGIONAL de ODONTOLOGIA DE SANTA CATARINA, 2015)

O estágio de implementação e a atual estrutura e solidificação das práticas sociais no cuidado da saúde foi objeto de pesquisa realizada por Peres (2015). A análise da pesquisa permitiu categorizar o processo de trabalho das equipes em três vertentes. A primeira, com foco no usuário - acolhimento, vínculo, ampliação do acesso, priorização, corresponsabilização. As EqSF e ESB, ao or- 
ganizarem seu trabalho, utilizavam o acolhimento como o principal dispositivo para ampliar o acesso aos serviços e demonstraram compreensão do modelo assistencial proposto pela ESF. O tempo de experiência na atenção básica e o engajamento do profissional favoreceram a criação do vínculo. Profissionais engajados no sentido de qualificação para a saúde da população mostraram-se mais vinculados aos usuários e com maior envolvimento nas ações de saúde.

Na segunda vertente, dentre as ações de reorientação dos serviços com foco no processo de trabalho, foram identificadas reuniões de equipe, atividades compartilhadas, planejamento e avaliação de ações de saúde como principais estratégias na medida em que espaços coletivos próprios da equipe favoreceram a integração, a organização para sua área de abrangência e, principalmente, o planejamento das atividades grupais. Essa relação estabelecida nesses momentos contribuiu para a superação das relações hierarquizadas.

Na terceira vertente, foi possível identificar, como principais ações facilitadoras do trabalho da equipe, a existência de sistemas informatizados para a regulação, o prontuário eletrônico, presença de computadores com acesso a rede de dados, telefone, protocolos de atenção à saúde e fluxos de acesso definidos, além do conhecimento da norma para trabalhar com esses sistemas. Tais mecanismos promoveram para a equipe maior qualidade no desenvolvimento do trabalho e, para o usuário, uma maior equidade na oferta dos serviços.

Os estudos realizados em Florianópolis, em 2006, 2009 e 2014, sugerem que a política nacional de saúde bucal vem se consolidando ao longo dos anos no município. Por serem estudos qualitativos, cuja metodologia envolveu entrevistas e observações de campo, evidenciaram o contexto histórico e a compreensão dos participantes em cada período: a pesquisa realizada em 2006 permitiu compreender o início do processo de inserção da Saúde Bucal (SB) na ESF, em Florianópolis. O estudo de 2009 descreveu o período relativo aos cinco anos dessa inserção, e a pesquisa realizada em 2014 objetivou compreender as potencialidades e dificuldades de inserção da SB na ESF após 10 anos de adesão ao então PSF.

Como aspectos chaves para implementação da PNSB, em Florianópolis, destacam-se as mudanças ocorridas no processo de trabalho da ESB e a qualidade da APS desenvolvida no município, ao longo desses 10 anos. Destaca-se também a mudança do perfil dos profissionais, advinda da implementação das Novas Diretrizes Curriculares e de todas as políticas indutoras da formação em saúde que se sucederam promovendo a integração dos cursos da área da saúde 
da Universidade Federal de Santa Catarina com a Secretaria Municipal de Saúde. (CARCERERI et al., 2015; SOUZA; CARCERERI, 2O11)

O estudo de Conill (2002), ao analisar a implantação do PSF em Florianópolis, no período de 1994 a 2000, concluiu que parecem ter maior influência no processo o tempo de implantação, o tipo de movimento social existente na comunidade e as características dos profissionais.

Ainda que o município seja referência em APS no país, há muitos pontos a serem superados em prol da consolidação da PNSB bem como da ESF como modelo de atenção proposto para o SUS.

\section{Considerações finais}

Este capítulo buscou apresentar como tem se dado a implementação da política nacional de saúde bucal no seu componente atenção básica, a partir de revisão da literatura sobre o tema e da análise de três experiências municipais.

A partir de 1994, a ESF constituiu-se no país como principal estratégia de reorganização da atenção básica no SUS. O incentivo financeiro para a inclusão da ESB/ESF, estabelecido no final de 2000, configurou-se como principal elemento indutor desse processo no âmbito da saúde bucal. Ademais, o desenvolvimento da PNSB no âmbito municipal apresentou diferentes configurações a depender do contexto sócio-histórico, cultural, político-administrativo e do modelo de atenção à saúde adotado pelo município.

A inclusão tardia da saúde bucal na ESF, a formação dos profissionais de saúde bucal, em especial do CD, voltada para a prática clínica individual, centrada no modelo de atenção à saúde bucal privatista, bem como a tradição liberal da profissão, têm contribuído para uma integração ainda pequena da ESB no desenvolvimento de atividades da ESF e efetiva reversão do modelo de atenção à saúde. A prática dos profissionais de saúde bucal em grande parte continua centrada no atendimento curativo-restaurador individual e na priorização da população escolar para a realização de atividades de promoção da saúde e prevenção dos principais agravos de saúde bucal.

Mais de 90\% dos municípios do país já possuem ESB/ESF, mas ainda há um número reduzido de ESB modalidade II implantadas, e não parece haver interesse ou mesmo uma política de ampliação de cobertura nessa modalidade. Entretanto, considerando-se a relação custo-benefício do uso de pessoal auxiliar em odontologia, a escassez de recursos financeiros no setor público e 
a necessidade de tratamento acumulada da população, essa estratégia torna-se fundamental para a expansão da cobertura dos serviços de saúde bucal.

Há que se destacar que houve uma ampliação da oferta e utilização de serviços odontológicos, contudo ela ainda é insuficiente. Estudos que comparam o desempenho de indicadores de saúde bucal de áreas cobertas e não cobertas por ESB/ESF não evidenciaram necessariamente melhor desempenho em áreas cobertas pela ESF. É necessário, então, refletir que fatores estariam influenciando esses resultados.

A simples adesão ao incentivo financeiro não implica em decisão política de reversão do modelo de atenção à saúde. Bem como a não adesão não implica em manutenção do modelo hegemônico. Nesse sentido, a decisão política do nível local em organizar o sistema de saúde tendo como fundamento a APS com território de atuação definido, com população adstrita, acesso universal e contínuo aos serviços de saúde, com vínculo e corresponsabilização, participação da comunidade, é mais decisiva que a adesão a um incentivo financeiro. Ou seja, é possível um município adotar essas premissas sem aderir ao incentivo e obter bons resultados, mas a recíproca (aderir ao incentivo e não adotar essas diretrizes organizativas) não é verdadeira. Como no caso do município de Vitória da Conquista, que não apresentou melhores resultados em áreas cobertas por ESB/ESF, mas, comparado a 12 outros municípios, teve menor necessidade de tratamento em áreas cobertas e descobertas e maior percentual da população com acesso a serviços públicos de saúde bucal.

Por outro lado, o êxito de uma política pública está relacionada também às características dos trabalhadores que a implementam, bem como a articulação coerente entre um projeto de governo transformador, a alta capacidade de governo na condução do processo, e sua governabilidade. No caso da ESF, mudanças importantes na formação ainda estão em curso. Em que pese os esforços realizados pelos cursos de graduação na área da saúde para formar profissionais aptos ao trabalho em equipe interdisciplinar, ainda há um longo caminho a ser trilhado nessa direção. Faz-se necessário diminuir a carga horária de disciplinas, abrindo espaços para as interdisciplinas e estágios multiprofissionais. O Programa de Educação pelo Trabalho Saúde da Família configurou-se em alternativa relevante para que esse objetivo seja atingido. Assim como, em nível de pós-graduação, destacam-se os cursos de Residência Multiprofissional em Saúde da Família. 
Nesse sentido, visando à consolidação da PNSB, destaca-se também a importância do fortalecimento contínuo da integração ensino-serviço-comunidade como estratégia de formação inicial na área da saúde e, também de educação permanente dos trabalhadores da saúde, entendendo a saúde bucal como uma área de ação multiprofissional e interdisciplinar.

\section{Referências}

ANDRADE, K.; FERREIRA, E. Avaliação da inserção da odontologia no Programa Saúde da Família de Pompéu (MG): a satisfação do usuário. Ciência \& Saúde Coletiva, Rio de Janeiro, v.11, n. 1., p. 123-130. 2006.

ANTUNES J.; NARVAI P. Políticas de saúde bucal no Brasil e seu impacto sobre as desigualdades em saúde. Revista Saúde Pública, Rio de Janeiro, v. 44, n. 2, p. 360-5. 2010.

AQUINO, R. et al. Estratégia saúde da família e reordenamento do sistema de serviços de saúde. In: PAIM, J. S.; ALMEIDA-FILHO, N. Saúde Coletiva: teoria e prática. Rio de Janeiro: Medbook, 2014. Cap. 25 p. 353-371.

BALDANI, M. et al. A inclusão da odontologia no Programa Saúde da Família no Estado do Paraná, Brasil. Cadernos de Saúde Pública, Rio de Janeiro, v. 21, n. 4, p. 1026-1035. 2005.

BALDANI, M. et al. Serviços públicos odontológicos: provisão e equidade no Estado do Paraná, Brasil. Revista Saúde Pública, Rio de Janeiro, v. 43, n. 3, p. 446- 54. 2009

BRASIL. Ministério da Saúde. Relatório Final da $1^{a}$ Conferência Nacional de Saúde Bucal. Brasília, DF., 1986.

BRASIL. Ministério da Saúde. Relatório Final da $2^{a}$ Conferência Nacional de Saúde Bucal. Brasília, DF., 1993.

BRASIL. Ministério da Saúde. Secretaria da Assistência à Saúde. Coordenação da Saúde e Comunidade. Saúde da Família: uma estratégia de reorientação do modelo assistencial. Brasília, DF, 1997a.

BRASIL. Ministério da Saúde. Portaria no 1886 GM/MS, de 18 de dezembro de 1997. Aprova as normas e diretrizes do Programa de Agentes Comunitários de Saúde e do Programa de Saúde da Família. Diário Oficial [da] República Federaltiva do Brasil, Brasílis, DF, 22 dez. 1997, sec. 1, p. 11 (BRASIL, 1997b)

BRASIL. Ministério da Saúde. Portaria no 1.444 GM/MS, de 28 de dezembro de 2000. Estabelece incentivo financeiro para a reorganização da atenção à saúde bucal prestadas nos municípios por meio do programa de saúde da família. Diário Oficial [da] República Federativa do Brasil, Brasília, DF, 29 dez. 2000, sec. 1, p. 85

BRASIL. Ministério da Saúde. Secretaria de Atenção à Saúde. Departamento de Atenção Básica.Coordenação Nacional de Saúde Bucal. Diretrizes da Política Nacional de Saúde Bucal. Brasília, DF, 2004a. 
BRASIL. Ministério da Saúde. Secretaria de Atenção à Saúde. Departamento de Atenção Básica. Projeto SB Brasil 2003: condições de saúde bucal da população brasileira 2002-2003: resultados principais. Brasília, DF, 2004b.

BRASIL. Ministério da Saúde. Secretaria de Atenção Básica. Departamento deAtenção Básica. Política Nacional de Atenção Básica. Brasília: Ministério da Saúde; 2007.

BRASIL. Ministério da Saúde. Portaria no 2.488 GM/MS, de 21 de outubro de 2011. Aprova a Política Nacional de Atenção Básica, estabelecendo a revisão de diretrizes e normas para a organização da Atenção Básica, para a Estratégia Saúde da Família (ESF) e o Programa de Agentes Comunitários de Saúde (PACS). Diário Oficial [da] República Federativa do Brasil, Brasília, DF, 24 out. 2011, sec.1, p. 48.

BRASIL. Ministério da Saúde. Secretaria de Atenção à Saúde. Secretaria de Vigilância em Saúde.SB Brasil 2010: Pesquisa Nacional de Saúde Bucal: resultados principais. Brasília, DF, 2012a.

BRASIL. Ministério da Saúde. Secretaria de Atenção à Saúde. Departamento de Atenção Básica. Política Nacional de Atenção Básica. Brasília, DF, 2012b.

BRASIL. Ministério da Saúde. Secretaria de Atenção à Saúde. Departamento de Atenção Básica. Florianópolis atinge 100\% de cobertura da Atenção Básica com a Estratégia de Saúde da Família. Notícias. 1998. Disponível em: <http://dab.saude.gov.br/portaldab/ noticias.php?conteudo=_\&cod=1998>. Acesso em: 19 set. 2015

BRASIL. Ministério da Saúde. Secretaria de Atenção à Saúde. Departamento de Atenção Básica. Histórico de cobertura da Saúde da Família. 2015. Disponível em: <http//:dab.saude. gov.br/portaldab/histórico_cobertura_sf.php>. Acesso em: 5 out. 2015.

CALADO, G. S. A inserção da equipe de saúde bucal no Programa de Saúde da Família: principais avanços e desafios. 122 f. Dissertação (Mestrado em Saúde Pública) - Escola Nacional de Saúde Pública, Fundação Oswaldo Cruz, Rio de Janeiro, 2002.

CARCERERI, D. L. et. al. Formação em odontologia e interdisciplinaridade: o Pró-Saúde da UFSC. Revista da ABENO, Camaragibe, v. 11, n. 1, p. 62-70. 2011.

CARCERERI, D. L. et. al. Estudo Prospectivo sobre a gestão de competências na área de odontologia no contexto do Sistema Único de Saúde/SUS, no Estado de Santa Catarina. Tese (Doutorado em Engenharia de Produção) - Centro Tecnológico, Universidade Federal de Santa Catarina, 2005.

CHAVES, S. C. L.; CRUZ, D. N. Desafios contemporâneos à organização da atenção em saúde bucal na Bahia. Revista Baiana de Saúde Pública, Salvador, v. 36 n. 1, p.621-639, 2012.

CHAVES, S. et al. Características do acesso e utilização de serviços públicos odontológicos em municípios de médio porte. Ciência \& Saúde Coletiva, Rio de Janeiro, v. 17, p. 3119-3128, 2012.

CHAVES, S. et al. Análise de políticas de saúde bucal no Brasil. A política nacional de saúde bucal no período 2003 a 2013: breves considerações sobre cenário e implementação. PAIM, J. (Coord). Observatório de análise política em saúde. Relatório 
acompanhamento de políticas. Marco zero antecedentes da política Disponível em <http:// analisepoliticaemsaude.org/oaps/matriz/>. Acesso em: 23 ago. 2015.

CONILL, E. M. Políticas de atenção primária e reformas sanitárias: discutindo a avaliação a partir da análise do Programa Saúde da Família em Florianópolis, Santa Catarina, Brasil, 1994-2000. Cadernos de Saúde Pública, Rio de Janeiro, 18(Suplemento):191-202, 2002.

CONSELHO REGIONAL DE ODONTOLOGIA DE SANTA CATARINA - CROSC. Conselho Federal de Odontologia divulga municípios vencedores do Prêmio Brasil Sorridente. 2015. Disponível em: <http://www.crosc.org.br/2015/08/premio-brasilsorridente-3>. Acesso em: 19 set. 2015.

COSTA, S.; ARAUJO, F. Dental auxiliaries versus community health workers: similarities and contrasts. Revista de Odontologia, São Paulo, v. 42, n. 5, p. 350-356. 2013.

EMMI, D.; BARROSO, R. Avaliação das ações de saúde bucal no Programa Saúde da Família no distrito de Mosqueiro, Pará. Ciência \& Saúde Coletiva, Rio de Janeiro, v. 13, n. 1, p. 35-41, jan/fev. 2008.

FACCIN, D.; SEBOLD, R. Processo de trabalho em saúde bucal: em busca de diferentes olhares para compreender e transformar a realidade. 2006. $62 \mathrm{f}$. Trabalho de Conclusão de Curso (Especialização em Saúde da Família - Modalidade Residência) - Curso de Especialização Multiprofissional em Saúde da Família,Universidade Federal de Santa Catarina, Florianópolis, 2006.

FACCIN, D.; SEBOLD, R.; CARCERERI, D. Processo de trabalho em saúde bucal: em busca de diferentes olhares para compreender e transformar a realidade. Ciência \& Saúde Coletiva, Rio de Janeiro, v. 15, suppl.1, p. 1643-1652. 2010.

FARIAS, M.; SAMPAIO, J. Integração da equipe de saúde bucal na Estratégia Saúde daFamília: A percepção dos profissionais. Revista Baiana de Saúde Pública, Salvador, v. 34, n. 4, 2011.

FERREIRA, P. H. Integralidade da atenção nas relações de saúde geral/geral na estratégia saúde da família. 151 f. Dissertação (Mestrado em Odontologia em Saúde Coletiva) - Centro de Ciências da Saúde, Universidade Federal de Santa Catarina, Florianópolis, 2010.

HENRIQUE, F; CALVO, M. C. M. Avaliação do Programa Saúde da Família nosmunicípios do Estado de Santa Catarina, Brasil. Cadernos de Saúde Pública, Rio de Janeiro, v. 24, h.4, p. 809-819, abr, 2008.

IBGE. Pesquisa Nacional por Amostra de Domicílios 1998: Acesso y utilização de serviços de saúde. Rio de Janeiro, 2000.

IBGE. Pesquisa Nacional por Amostra de Domicílios 2008. Vol. 29. Rio de Janeiro, 2008.

IOM. Instituteof Medicine. A manpower policy for primary health care. IOM Publication 78-02. Washington DC. National Academy of Sciences, 1978.

JUNIOR, M. Avaliação de desempenho da política nacional de saúde bucal no período de 20042010. 2013. 89 f. Dissertação (Mestrado em Ciências da Saúde) - Faculdade de Ciências da Saúde, Universidade de Brasília. Brasília, DF, 2013. 
KORNIS, G.; MAIA, L. e FORTUNA, R. Evolução do financiamento da atenção à saúde bucal no SUS: uma análise do processo de reorganização assistencial frente aos incentivos federais. Physis, Rio de Janeiro, v. 21, n. 1, p. 197-215. 2011.

LOURENÇO, E. C. et al. A inserção das equipes de saúde bucal no programa de saúde no estado de MG. Ciência \& Saúde Coletiva, Rio de Janeiro, v. 14, suppl.1, p. 1367-1377. 2009.

MARTELLI, P. et al. Análise do modelo de atenção à saúde bucal em municípios do estado de Pernambuco. Ciência \& Saúde Coletiva, Rio de Janeiro, v. 13, n. 5, p. 1669-1674, 2008.

MARTELLI, P. Política Nacional de Saúde Bucal, da teoria a prática: Um estudo de caso acerca de sua implantação em Recife PE no período de 2000 a 2007. 2010. 235 f. Tese (Doutorado em Saúde Pública) - Centro de Pesquisas Aggeu Magalhães, Fundação Oswaldo Cruz, Recife, 2010.

MATTOS, G. et al. A inclusão da equipe de saúde bucal na Estratégia Saúde daFamília: entraves, avanços e desafios. Ciência \& Saúde Coletiva, Rio de Janeiro, v. 19, n. 2, p. 373-382, 2014.

MENDES, J. M. R; LEWGOY, A. M. B; SILVEIRA, E. C. Saúde e interdisciplinaridade: mundo vasto mundo. Revista Ciência \& Saúde, Porto Alegre, v. 1, n. 1, p. 24-32, jan./jun. 2008.

MOURA, M. et al. Saúde bucal na estratégia de saúde da família em um colegiado gestor regional do estado do Piauí. Ciência \& Saúde Coletiva, Rio de Janeiro, v. 18, n. 2, p. 471-48o, 2013.

MUNKEVITZ, M. E.; PELICIONI, M. Saúde bucal na Estratégia Saúde da Família no município de São Paulo: perspectiva do usuário. Revista brasileira de crescimento e desenvolvimento humano. São Pualo, v. 20, n. 3, 2010.

NASCIMENTO, A. et al. Oral health in the family health strategy: a change of practices or semantics diversionism. Revista de Saúde Pública, São Paulo, v. 43, n. 3, p. 455-462, Mar., 2009

NARVAI, P.C.; CARCERERI, D. L. Salud Bucal Colectivaen Brasil. In: Castaño-Séiquer A; Ribas-Pérez D. (Org.). Odontología preventiva y comunitaria: laodontología social. Undeber, una necesidad, um reto. Madrid: Fundación Odontología Social, 2012. p. 843-854.

NARVAI, P.; FRAZÃO, P. Saúde bucal no Brasil muito além do céu da boca. Rio de Janeiro: Editora Fiocruz, 2008. 148 p.

OLIVEIRA, R. S. et al. Use of dental services in areas covered by the Family Health Strategy in Olinda, Brazil. Cadernos de Saúde Coletiva, Rio de Janeiro, v. 22, n. 1, p. 40-45, 2014 .

OLIVEIRA, A. G. R. DA COSTA. Banco de dados do projeto "Impacto do Programa Saúde da Família no perfil de saúde bucal: análise em municípios do Nodeste com mais de 100.000 habitantes", Natal, [2005]. 
ORGANIZAÇÃO PANAMERICANA DE SAÚDE (OPAS). Discussão sobre o marco conceitual e referencial da atenção básica e saúde dafamília no Brasil. Brasília, DF, 2003. Disponível em: $<$ http//www.opas.org.br/serviço/arquivos/Sala5309.pdf>. Acesso em: 19 set. 2015.

PADULA, M.; AGUILAR-DA-SILVA, R. Professional profile of dentists who are members of the Family Health Strategy city of Marília, São Paulo: the challenge of interprofessional work. Revista de Odontologia, São Paulo, v. 43, n. 1, p. 52-60. 2014.

PAIM, J. S. et al. O sistema de saúde brasileiro: história, avanços e desafios. The Lancet, p. 11-31. 2011. Disponível em:

<http://www5.ensp.fiocruz.br/biblioteca/dados/txt_822103381.pdf> Acesso em : Acesso em: 23 ago. 2015

PAIM, J. S. O objeto e a prática da Saúde Coletiva: o campodemanda um novo profissional? Salvador: ISC/UFBA, 2002.

PALACIO, D. C. et al. Evolução de indicadores pós-implantação da saúde bucal na Estratégia Saúde da Família. Einstein, São Paulo, v. 12, n. 3, p. 274-281, 2014.

PEREIRA, C. R. et al. Impacto da Estratégia Saúde da Família com equipe de saúde bucal sobre a utilização de serviços odontológicos. Cadernos de Saúde Pública, Rio de Janeiro, v. 25 , n. 5, p. 985-996, 2009.

PEREIRA, C. R. et al. Impacto da Estratégia Saúde da Família sobre indicadores de saúde bucal: analise em municípios do nordeste brasileiro com mais de 100 mil habitantes. Cadernos de Saúde Pública, Rio de Janeiro, v. 28, n. 3, p. 449-62. 2012.

PERES, A. C. O., O trabalho interdisciplinar como inovação tecnológica na promoção da saúde: estudo qualitativo na atenção primária, em Florianópolis-SC. 2015. 80 f. Dissertação (Mestrado em Odontologia em Saúde Coletiva) - Centro de Ciências da Saúde, Universidade Federal de Santa Catarina, Florianópolis, 2015.

PIMENTEL, F. C. et al. Análise da atenção à saúde bucal na Estratégia de Saúde da Família do Distrito Sanitário VI, Recife (PE). Ciência \& Saúde Coletiva, Rio de Janeiro v.15, n. 4, p. 2189-2196, 2010.

PIMENTEL, F. C. et al. Análise dos indicadores de saúde bucal do estado de Pernambuco: desempenho dos municípios segundo porte populacional, população cadastrada no Sistema de Informação da Atenção Básica e proporção na Estratégia Saúde da Família. Cadernos Saúde Coletiva, Rio de Janeiro, v. 22, n. 1, p. 54-61, 2014.

REIS, W. G. ; SCHERER, M. D. A. ; CARCERERI, D.L. O trabalho do cirurgião-dentista na atenção primária de saúde: entre o prescrito e o real. Saúde em Debate, São Paulo, v. 39, p. 56-64, 2015 .

ROCHA, R. A. C. P.; GOES, P. S. A. Comparação do acesso aos serviços de saúde bucal em áreas cobertas e não cobertas pela Estratégia Saúde da Família em Campina Grande, Paraíba, Brasil. Cadernos de Saúde Pública, Rio de Janeiro, v. 24, n. 12, p. 2871-2880, 2008. 
SANTOS, A. et al. Linhas de tensões no processo de acolhimento das equipes de saúde bucal do Programa Saúde da Família: o caso de Alagoinhas, Bahia, Brasil. Cadernos de Saúde Pública, Rio de Janeiro, v. 23, n.1, p. 75-8, 2007.

SANTA CATARINA. SECRETARIA ESTADUAL DE SAÚDE. Estratégia Saúde da Família está presenteem todos os municípios do Estado. Revista Catarinense de Saúde da Família. Florianópolis, Ano I n. 1, p. 6-7, nov. 2009. Disponível em: <http://www.youblisher.com/ p/494381-1-Revista-Catarinense-de-Saude-da-Familia>. Acesso em: 19 set. 2015.

SILVA, S. et al. Análise do avanço das equipes de saúde bucal inseridas na Estratégia Saúde da Família em Pernambuco, região Nordeste, Brasil, 2002 a 2005. Ciência e saúde coletiva, v. 16, n.1, p. 211-220, 2011.

SILVESTRE, J.; DE AGUIAR, A.; TEIXEIRA, E. Do Brasil sem Dentes ao Brasil Sorridente: Um resgate histórico das políticas públicas de saúde bucal no Brasil. Cadernos ESP, Ceará, v. 7, n. 2, p. 28-39, jul./dez. 2013.

SISSON, M. C. et. al. Estratégia de Saúde da Família em Florianópolis: integração, coordenação e posição na rede assistencial. Saúde e Sociedade, São Paulo, v. 20, n. 4, p.9911004, 2011.

SOARES, F. et al. Atuação da equipe de saúde bucal na estratégia saúde da família: análise dos estudos publicados no período 2001-2008. Ciência \& Saúde Coletiva, Rio de Janeiro, v. 16, n. 7, p. 3169-3180, 2011.

SOARES, F., et al. Desigualdade na utilização de serviços de saúde bucal na atenção básica e fatores associados em dois municípios brasileiros.

Revista panamericana de salud pública, Washington, D.C., v. 34, n. 6, p. 401-6, 2013.

SOARES, C. L. M.; PAIM, J. S. Aspectos críticos para a implementação da política de saúde bucal no Município de Salvador, Bahia, Brasil. Cadernos de SaúdePública, Rio de Janeiro, v. 27, n. 5, p. 966-974, maio, 2011.

SOUZA, A. L; CARCERERI, D. L. Estudo qualitativo da integração ensino-serviço em um curso de graduação em Odontologia. Interface - Comunicação, Saúde, Educação, Botucatu, v. 15 , n. 39, p. 1071-84, out./dez. 2011.

SOUZA, T. M. S.; RONCALLI, A. G. Saúde bucal no Programa Saúde da Família: uma avaliação do modelo assistencial. Cadernos de Saúde Pública, Rio de Janeiro, v. 23, p. 27272739. 2007 .

STARFIELD, B. Measuring the attainment of primary care. Journal of Medical Education. V. 54, n. 5, p. 361-369. 1979.

STARFIELD, B. Atenção primária de saúde: equilíbrio entre necessidades de saúde, serviços e tecnologia. Brasília, DF: UNESCO; Ministério da Saúde, 2002.

TAVARES, R. et al. A organização do acesso aos serviços de saúde bucal na estratégia de saúde da família de um município da Bahia. Saúde em debate, São Paulo, v. .37, n. 99, p. 628635. 2013 . 
VIANA, A.; DAL POZ, M. R. A reforma sanitária do sistema de saúde no Brasil e Programa Saúde da Família. Physis, Rio de Janeiro, v. 2, p. 225-264, 1998.

VILASBOAS, A., et al. Estudos e pesquisa em Atenção primaria e promoção da saúde. Atenção primária e promoção da saúde no Brasil: origens e situação atual. In: PAIM, J. (Coord). Observatorio de análise política em saúde. Relatório acompanhamento de políticas.

Marco Zero antecedentes da política. Disponível em: <http://analisepoliticaemsaude.org/ oaps/matriz/>. Acesso em: 23 ago. 2015.

ZANETTI, C. As marcas de mal-estar social no sistema nacional de saúde tardio: o caso das políticas de saúde bucal no Brasil dos anos 80. 1993. 134 f. Dissertação (Mestrado em Saúde Pública) -Escuela Nacional de Saúde Pública, Fundação Oswaldo Cruz, Rio de Janeiro, 1993. 